\title{
Extrahepatic Bile Duct Adenocarcinoma
}

National Cancer Institute

\section{Source}

National Cancer Institute. Extrahepatic Bile Duct Adenocarcinoma. NCI Thesaurus. Code C7975.

An adenocarcinoma arising from the epithelium of the extrahepatic bile ducts. Signs and symptoms include abdominal pain, anorexia, jaundice, pruritus, nausea and vomiting, and weight loss. 